\title{
PROTEASES
}

\section{Potential Role in Health and Disease}

Edited by

Walter H. Hörl

and

August Heidland

University of Würzburg

Würzburg, Federal Republic of Germany 


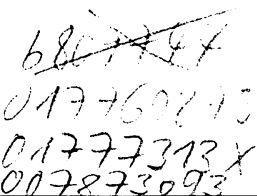

Library of Congress Cataloging in Publication Data

International Symposium on Proteases: Potential Role in Health and Disease (1982: Würzburg, Germany)

Proteases, potential role in health and disease.

(Advances in experimental medicine and biology; v. 167)

"Proceedings of the International Symposium on Proteases: Potential Role in Health and Disease, held October 17-20, 1982, in Würzburg, Federal Republic of Germany"Verso t.p.

Includes bibliographical references and index.

1. Proteolytic enzymes-Congresses. 2. Proteolytic enzyme inhibitors-Congresses. I. Hörl, Walter H. II. Heidland, August. III. Series. [DNLM: 1. Protease inhibitors Congresses. 2. Peptide hydrolases-Congresses. W1 AD559 v.167 / QU 136 I615p 1982]

QP609.P78I57 1982

$599^{\prime} .019256$

$83-19186$ ISBN 0-306-41488-0

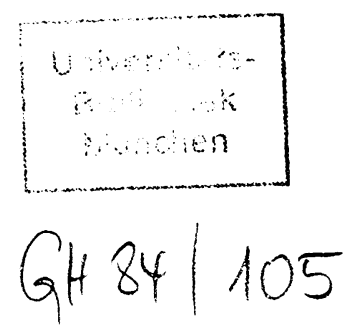

Proceedings of the International Symposium on Proteases: Potential Role in Health and Disease, held October 17-20, 1982, in Würzburg, Federal Republic of Germany

\section{(C) 1984 Plenum Press, New York}

A Division of Plenum Publishing Corporation

233 Spring Street, New York, N.Y. 10013

All rights reserved

No part of this book may be reproduced, stored in a retrieval system, or transmitted in any form or by any means, electronic, mechanical, photocopying, microfilming, recording, or otherwise, without written permission from the Publisher

Printed in the United States of America 


\section{CONTENTS}

\section{PHYSIOLOGY AND PATHOPHYSIOLOGY OF PROTEASES AND THEIR INHIBITORS}

Physiology and Pathophysiology of Neutral Proteinases

of Human Granulocytes ....................... 1

K. Havemann and M. Gramse

Regulation of Protease Activity

M. Steinbuch

Human Kininogens and Their Function in the Kallikrein-

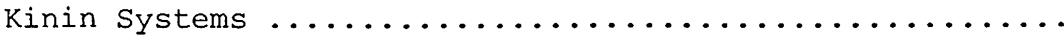

W. Müller-Esterl and H. Fritz

Possible Involvement of Kinins in Muscle Energy

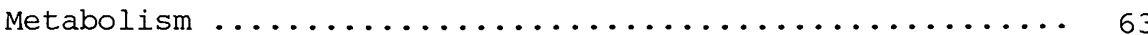

G. Dietze, E. Maerker, C. Lodri, R. Schifman,

M. Wicklmayr, R. Geiger, E. Fink, I. Boettger,

H. Fritz, and H. Mehnert

Structure and Function of Natural Inhibitors as

Antagonists of Proteinase Activities ............. 73

H. Tschesche

Oxidation of Alpha-1-Proteinase Inhibitor:

Significance for Pathobiology ................. 89

J. Travis, K. Beatty, and N. Matheson

In Vivo Significance of Kinetic Constants of Macromolecular Proteinase Inhibitors ............. 97

J. G. Bieth

On the Multiplicity of Cellular Elastases and their Inefficient Control by Natural Inhibitors ........... 111

W. Hornebeck, D. Brechemier, M. P. Jacob,

C. Frances, and L. Robert 
Proteases - Proteases Inhibitors: a Local

Cellular Information system $\ldots \ldots \ldots \ldots \ldots \ldots \ldots \ldots \ldots \ldots \ldots$

H. Heine

PROTEASES AND HORMONES

Regulatory Proteolysis during Corticosteroid

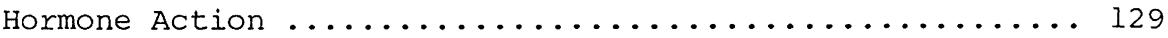

M. K. Agarwal

Proteases in Hormone Production and Metabolism

W. A. Hsueh

Precursor Processing and Metabolism of

Parathyroid Hormone: Regulation

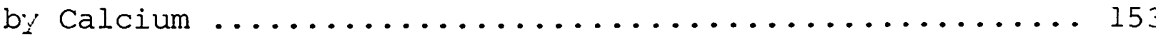

J. A. Fischer

Processing and Degradation of Met-Enkephalin

by Peptidase Associated with Rat Brain

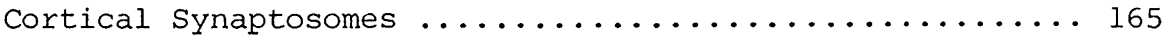

$\mathrm{W}$. Demmer and $\mathrm{K}$. Brand

PROTEASES IN KIDNEY AND INTESTINAL TRACT

Characterization and Clinical Significance of

Membrane Bound Proteases from Human

Kidney Cortex .............................. 179

J. E. Scherberich, C. GauhI, G. Heinert,

W. Mondorf, and W. Schoeppe

Recent Advances in Protease Research using

Synthetic substrates ....................... i9l

R. Gossrau, Z. Lojda, R. E. Smith, and

P. Sinha

Kinetic Characterization of Brush Border Membrane

Proteases in Relationship to Mucosal

Architecture by Section Biochemistry .............. 209

S. Gutschmidt, R. Hoper, and R. Gossrau

Fluorescence Detection of Proteases with AFC,

AMC and MNA Peptides using Isoelectric

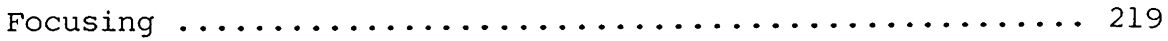

P. Sinha, R. Gossrau, R. E. Smith, and

Z. Lojda 
Pathophysiology of the Interaction between

Complement and Non-Complement

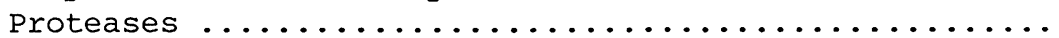

U. E. Nydegger and S. Suter

Interactions between the Alternative

Complement Pathway and Proteases

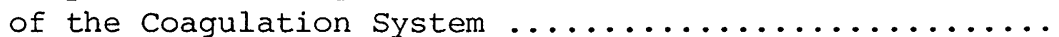

M. D. Kazatchkine and M.-H. Jouvin

The Calcium-Dependent Neutral Protease of Human Blood Platelets: a Comparison of its Effects on the Receptors for von Willebrand Factor and for the Fc-Fragment Derived from IgG $\ldots \ldots \ldots \ldots \ldots \ldots \ldots \ldots$

M. O. Spycher, U. E. Nydegger, and

E. F. Luescher

Alpha-2-Plasmin Inhibitor Inactivation by

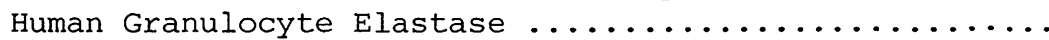

M. Gramse, K. Havemann, and R. Egbring

Heparin and Plasma Proteinase Inhibitors:

Influence of Heparin on the Inhibition

of Thrombin by $\alpha_{2}$ Macroglobulin $\ldots \ldots \ldots \ldots \ldots \ldots \ldots$

P. Lambin, F. Pochon, and M. Steinbuch

The Involvement of Plasmatic and Fibrinolytic

Systems in Idiopathic Glomerulonephritis (GN)

K. Andrassy, E. Ritz, and R. Waldherr

The Effect of Aprotinin on Platelet Function, Blood Coagulation and Blood Lactate Level in Total Hip Replacement - a

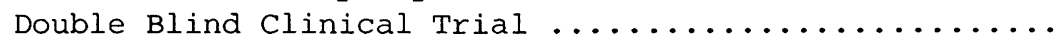

S. Haas, R. Ketterl, A. Stemberger, P. Wendt, H.-M. Fritsche, H. Kienzle,

F. Lechner, and G. Blümel

\section{PROTEASES AND LUNG}

Interaction of Granulocyte Proteases with Inhibitors j.n Pulmonary Diseases ...

K. Ohlsson, U. Fryksmark, M. Ohlsson, and $\mathrm{H}$. Tegner 
Leukoproteinases and Pulmonary Emphysema:

Cathepsin G and Other Chymotrypsin-

Like Proteinases Enhance the Elasto-

lytic Activity of Elastase on Lung

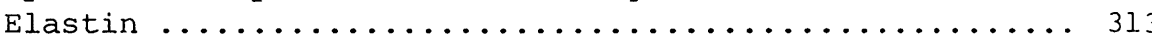

Ch. Boudier, Ph. Laurent, and J. G. Bieth

Adult Respiratory Distress Syndrome (ARDS):

Experimental Models with Elastase and

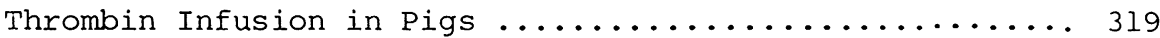

H. Burchardi, T. Stokke, I. Hensel, H. Köstering,

G. Rahlf, G. Schlag, H. Heine, and

W. H. Hörl

\section{PROTEASES AND ARTHRITIS}

Interactions of Granulocyte Proteases with

Inhibitors in Rheumatoid Arthritis ............. 335

L. Ekerot and $\mathrm{K}$. Ohlsson

Quantitation of Human Leukocyte Elastase,

Cathepsin G, $\alpha$-2-Macroglobulin and

a-1-Proteinase Inhibitor in Osteo-

arthrosis and Rheumatoid Arthritis

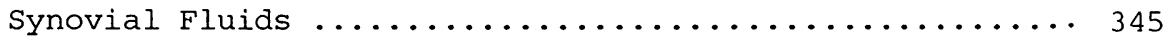

G. D. Virca, R. K. Mallya, M. B. Pepys,

and H. P. Schnebli

Plasma Levels of Inhibitor Bound Leukocytic

Llastase in Rheumatoid Arthritis

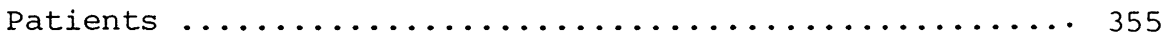

H. P. Schnebli, P. Christen, M. Jochum,

R. K. Mallya, and M. B. Pepys

$\mathrm{a}_{2}$ M-Pasebic Assay: a Solid Phase Immuno-

sorbent Assay to Characterize Alpha ${ }_{2}^{-}$

Macroglobulin - Proteinase Complexes

and the Proteinase Binding-Capacity

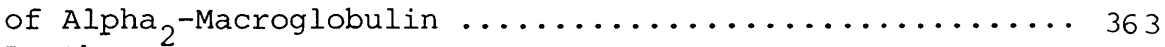

W. Borth

Role of $\mathrm{Alph}_{2}-$ Macroglobulin: Proteinase

Complexes in Pathogenesis of Inflammation:

' $F$ ' $a_{2} M$ but not ' $S$ ' $a_{2} M$ Induces Synovitis

in Rabbits after Repeated Intra-Articular

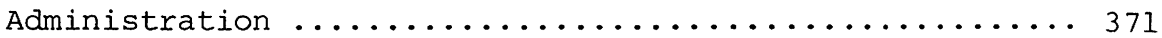

W. Borth and M. Susani 
Enzyme-Linked Immunoassay for Human Granulocyte Elastase in Complex with $\alpha_{1}$-Proteinase Inhibitor ............................... 379

S. Neumann, N. Hennrich, G. Gunzer, and H. Lang

Proteinases and their Inhibitors in Septicemia Basic Concepts and Clinical Implicationa ............. 391

M. Jochum, K.-H. Duswald, S. Neumann, J. Witte, and H. Fritz

Proteolytic Activity in Patients with Hypercatabolic Renal Failure .............................. 405

W. H. Hörl, R. M. Schäfer, K. Scheidhauer, M. Jochum, and A. Heidland

Release of Granulocyte Neutral Proteinases in Patients with Acute and Chronic Renal Failure ............................... 417

A. Heidland, W. H. Hörl, N. Heller, H. Heine, S. Neumann, and E. Heidbreder

Changes in Components of the Plasma KallikreinKinin and Fibrinolytic systems Induced by a Standardized Surgical Trauma ........

A. O. Aasen, J. Stadaas, T. E. Ruud, and

P. Kierulf

Endotoxins and Coagulation Parameters in Patients with Traumatic Haemorrhagic- and Bacterio-

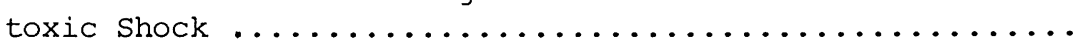

A. Stemberger, F. Strasser, G. Blümel, B. V. Hundelshausen, S. Jelen, O. Schmidt, and G. Tempel

Studies on Pathological Plasma Proteolysis in Severely Burned Patients using Chromogenic Peptide Substrate Assays: A Preliminary

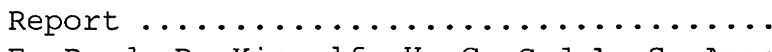

T. E. Ruud, P. Kierulf, H. C. Godal, S. Aune, and A. O. Aasen

Changes in Components of the Plasma Protease Systems Related to Course and outcome

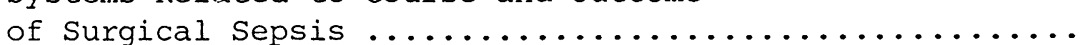

N. Smith-Erichsen, A. O. Aasen, and E. Amundsen 


\section{PANCREATITIS}

Role of Proteases in the Development of

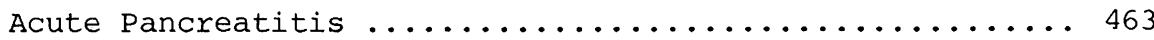

M. Wanke

On the Potential Role of Trypsin and Trypsin

Inhibitors in Acute Pancreatitis .............. 477

A. Lasson and $\mathrm{K}$. Ohlsson

Studies on the Kallikrein-Kinin System in

Plasma and Peritoneal Fluid during

Experimental Pancreatitis ................... 489

T. E. Ruud, A. O. Aasen, P. Kierulf,

J. Stadaas, and S. Aune

The Influence of the Kallikrein-Kinin System

in the Development of the Pancreatic

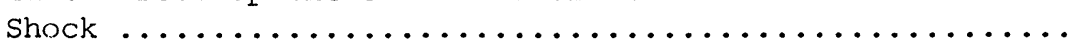

H. Kortmann, E. Fink, and G. Bönner

PROTEASES AND MUSCLE FUNCTION

Proteolytic Enzymes and Enhanced Muscle

Protein Breakdown ......................... 505

B. Dahlmann, L. Kuehn, and H. Reinauer

$\mathrm{Ca}^{2}$-Activated Proteinases, Protein Degradation and Muscular Dystrophy ............................. 519

J. Kay

Muscle Cathepsin D Activity, and RNA, DNA and Protein Content in Maintenance Hemo-

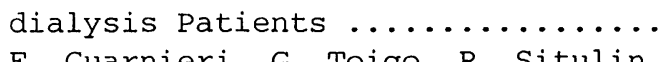

G. F. Guarnieri, G. Toigo, R. Situlin, L. Faccini, R. Rustia, and F. Dardi

Enhanced Muscle Protein Degradation and Amino

Acid Release from the Hemicorpus of

Acutely Uremic Rats ...................... 545

R. M. Flugel-Link, I. B. Salusky,

M. R. Jones, and J. D. Kopple

Enhanced Muscle Protein Catabolism in Uremia

H. R. Harter, T. A. Davis, and I. E. Karl 
Catabolic Stress on Intracellular Amino Acid

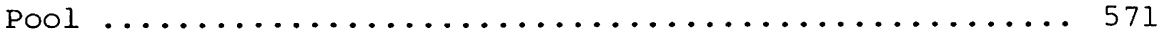

P. Fürst

Rhabdomyolysis: a Clinical Entity for the

Study of Role of Proteases ................... 581

S. G. Massry

INDEX 
H. P. Schneblil, P. Christen ${ }^{1}$, M. Jochum ${ }^{2}$,

R. K. Mallya ${ }^{3}$ and M. B. Pepys 4

1 Research Department, Pharma Division, Ciba-Geigy, $\mathrm{CH}-4002$ Basel, Abt. Klinische Chemie, Chiruुrgische Klinik, Universität München, D-8000 Munich. ${ }^{3}$ Dept. Rheumatology, Kings College Hospital, London, SE 5. Immunological Medicine Unit, Dept. Medicine, Royal Postgraduate Medical School, London, W12, OH5

\section{INTRODUCTION}

It is generally agreed that: (a) massive numbers of PMN leukocytes accumulate at sites of chronic inflammation (1), and in inflammatory synovial fluids (2), (b) these PMN leukocytes release elastase (3) as well as a number of other enzymes and inflammatory mediators (4) during phagocytosis or other mechanisms (5), (c) substantial quantities of elastase have been identified in the synovium $(6,7)$ or, complexed to naturally occuring inhibitors in synovial fluids of RA patients (8-12) or penetrated into the articular cartilage $(13,14)$.

Without entering the debate as to whether or not leukocytic elastase is responsible for tissue destruction in RA and other inflammatory diseases (for a review see Barrett, ref. 15), we have taken the findings listed above to suggest that leukocytic elastase released at sites of inflammation may lead to elevated plasma levels of this enzyme.

Indeed, elevated plasma levels of leukocyte elastase - $\alpha_{1} P I$ complexes have previously been observed (16) and subsequently followed up in more detail (17) in patients with leukemia or septicaemia. Increased levels of elastase $-\alpha_{2} M$ complexes were also found in septicaemic patients (18). 
In the present study we measured the plasma levels of elastase - $\alpha_{1}$ PI complexes by an immunological technique (ELISA) (Method A) and of $\alpha_{2} \mathrm{M}$ bound elastase with a synthetic chromogenic substrate (Method B) in RA patients $(n=87)$ and healthy controls $(n=24)$.

\section{PATIENTS AND METHODS}

Twenty seven male and 60 female patients suffering from rheumatoid arthritis according to the criteria of the American Rheumatism Association were studied. Their disease activity was assessed by a new multivariate analysis comprising the following criteria: morning stiffness, pain scale, grip strength, articular index, haemoglobin concentration and erythrocyte sedimentation rate (19). On the basis of their global score in the analysis the patients were assigned to one of four grades of disease activity (MDAG 1-4).

Blood samples were drawn into EDTA-coated tubes and centrifuged immediately in order to remove cells; plasma was then stored at $-20^{\circ}$ until assayed.

Levels of immunreactive elastase in plasma were determined with a newly developed enzyme-linked immunoassay (ELISA) $(12,20)$. This method (Method A) measures exclusively the elastase complexed to $\alpha_{1}$ PI. Plasma samples were incubated in plastic tubes coated with ${ }^{1}$ antibodies against elastase. After washing with buffer, the surface fixed elastase- $\alpha$ PI complexes were reacted with anti- $\alpha_{1}$ PI antibodies labelled with alkaline phosphatase. Under the conditions used, the enzymatic activity of the alkaline phosphatase (assayed with p-nitrophenyl phosphate) was proportional to the concentration of elasatase- $\alpha_{1} P I$ complex in the sample. (For details of this assay, see ref. 20).

Leukocyte elastase activity in plasma was measured by a modification (18) of the procedure described earlier (21). In this assay (Method $B$ ) the release of $p$-nitroaniline from MethoxySuccinyl-L-Ala-L-Ala-L-Pro-L-Val-p-Nitroanilide (MeO-Suc-Ala-AlaPro-Val-pNA), a highly specific chromogenic substrate for leukocytic elastase (22), was determined photometrically; o-phenanthroline was included to inhibit an unrelated metal dependent elastase-like enzyme $(18,23)$. Briefly, $0.2 \mathrm{ml}$ of plasma was diluted with $0.2 \mathrm{ml}$ of buffer containing the substrate and the metal chelator; final concentrations: $0.1 \mathrm{M}$ Tris-HCl, $\mathrm{pH} 7.5,1 \mathrm{mM}$ MeO-Suc-Ala-Ala-Pro-Val-pNA and $10 \mathrm{mM}$ o-phenanthroline. The mixture was incubated at $37^{\circ}$ for 1 to 6 hours and the reaction. was stopped by the addition of $1 \mathrm{ml}$ trichloroacetic acid $(7.5 \%)$. Precipitated protein was removed by centrifugation and the released nitroaniline was transformed to an azo-dye by the sequential addition of $25 \mu l$ each of sodium nitrite ( $1.8 \%)$, 
ammonium sulphamate $(9 \%)$ and $\mathrm{N}-1$-naphtyl ethylene-diamine di-HCl $(1.8 \%)$ to the supernatant. The resulting color was measured at $550 \mathrm{~nm}$. The corresponding enzyme activity is expressed in nmoles/ $\mathrm{ml} / \mathrm{h}$ of substrate hydrolyzed.

\section{RESULTS AND DISCUSSION}

The present study was undertaken to determine whether the release of leukocyte elastase at sites of active inflammation is reflected in the plasma levels of this enzyme, and whether this may be diagnostically useful in RA. Two independent methods for the determination of HLE plasma levels were employed.

The design of the enzyme-linked immunoassay (20) ensures that only HLE bound to $\alpha$-proteinase inhibitor was measured (Method A). In our hands, the HLE levels in control plasma were compatible with the previously published values of $84 \pm 25 \mathrm{ng} / \mathrm{ml}$ (20) and $60 \mathrm{ng} / \mathrm{ml}$ (median value) (24) using the same assay system.
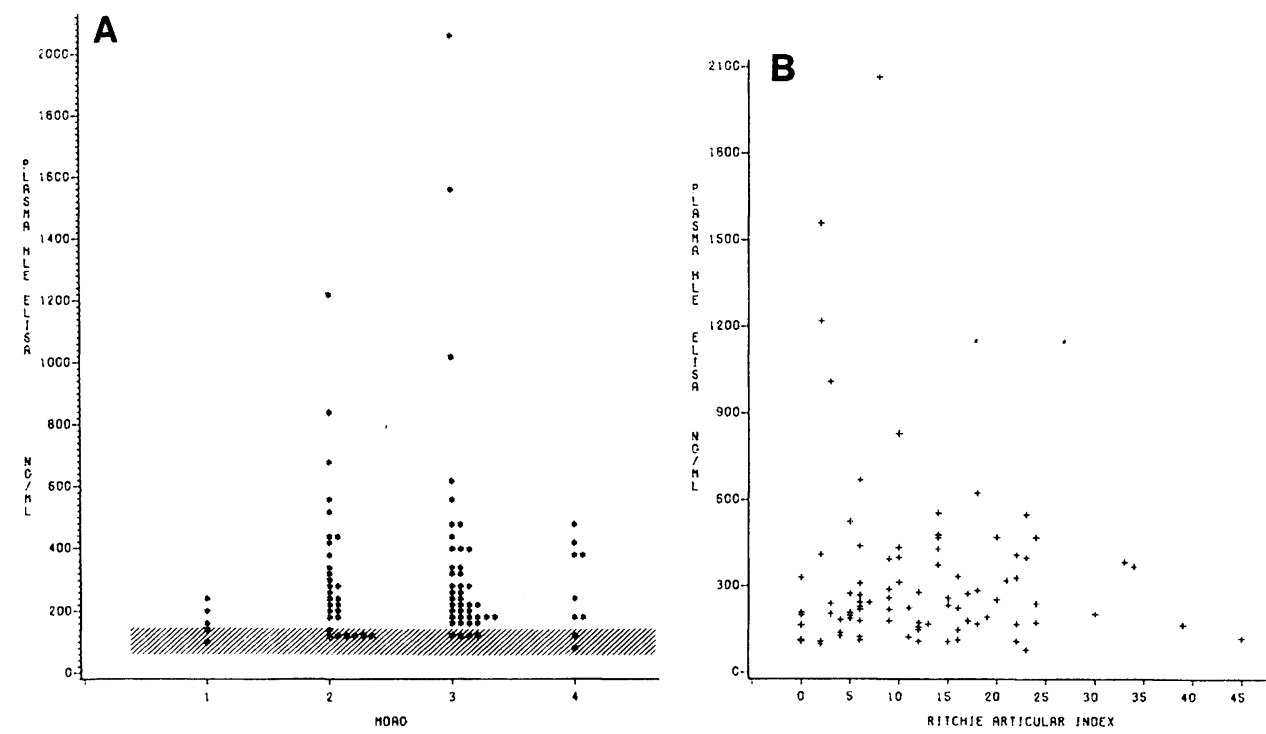

Fig. 1 HLE plasma levels measured immunologically as $\alpha_{1}$ PI complex in 87 RA patients: comparison with $\operatorname{MDAG}^{1}(\mathrm{~A})$, a weighted index of disease activity, or with the Ritchie articular index (B).

The majority of the plasma samples from RA patients had clearly elevated HLE- $\alpha$ PI levels (Fig. 1A); 65 of 87 samples revealed values more than 2 standard deviations above the normal mean value. However, as can be seen in the same figure, the HLE concentration in plasma does not correlate with the "mean disease activity grade (MDAG)" (19), a weighted index based on 6 disease 
parameters (see patients and methods) or with the Ritchie articular index (25) alone (Fig. 1 B). Interestingly, in the same patient collective, C-reactive protein (CRP) levels correlated well, both with the MDAG and the Ritchie index (26).
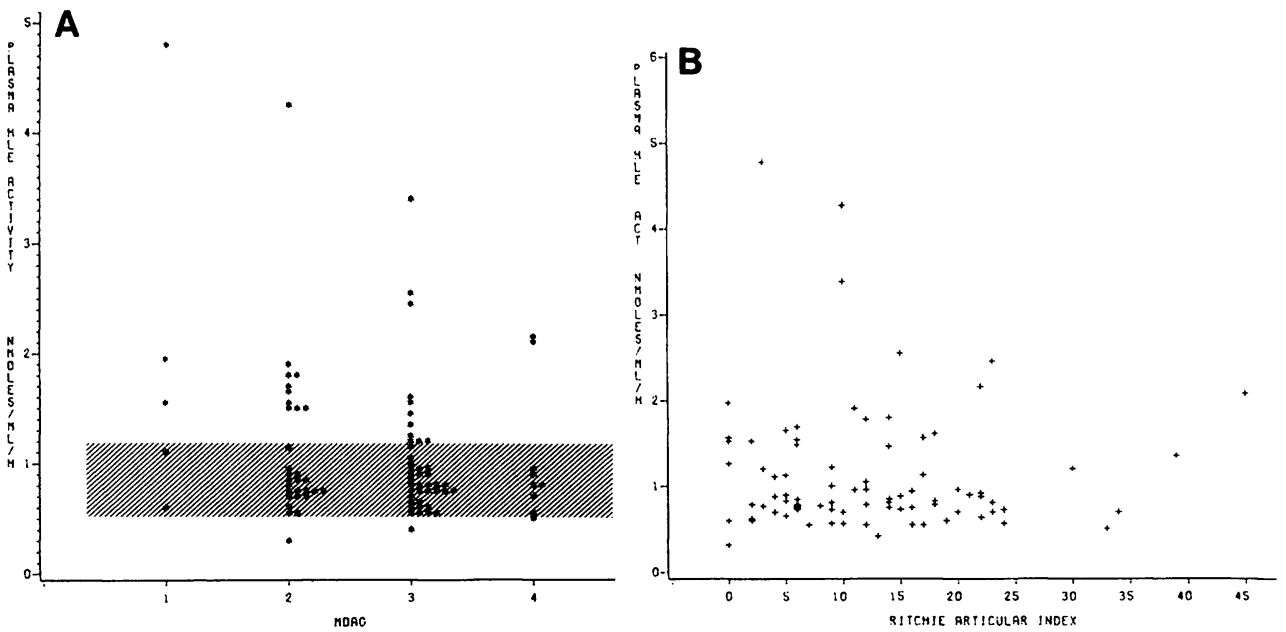

Fig. 2 HLE plasma levels measured as enzymic activity of $\alpha$ M complexes in $87 \mathrm{RA}$ patients: comparison with MDAG ( $($ ) or with the Ritchie articular index (B).

The measurement of elastase activity in plasma (Method B) is based on the fact that $\alpha_{2} M$ bound proteinases retain hydrolytic activity towards low $M$ substrates, though they are unable to attack most large (profein) substrates. As shown previously with plasma from septicaemic patients (18), this elastase activity can be separated from the bulk of plasma proteins on Sephacryl S300. The apparent molecular weight (approx. $800000 \mathrm{Da}$ ), the substrate specificity (MeO-Suc-Ala-Ala-Pro-Val-pNA) and the inhibition pattern (insensitive to EDTA and o-phenanthroline, sensitive to PMSF and the elastase specific inhibitor Eglin C) identifies this activity as leukocyte elastase $-\alpha{ }^{M}$ complex. Compared with plasma from 24 healthy controls, HLE activity was elevated in a number of plasma samples from RA patients (20 out of 87 samples were elevated more than 2 standard deviations above the normal mean) (Fig. 2A).

However, again no correlation could be found between plasma HLE activity levels and disease activity (Fig. 2). Furthermore the HLE- $\alpha_{1}$ PI levels (Method A) and the HLE- $\alpha_{2}$ M levels (Method B) did not correlate ( $R<0.1, \mathrm{Fig} .3)$.

It must be stressed that the levels of elastase activity in plasma are very low, requiring a sensitive assay and prolonged reaction times (see methods). Normal plasma ( $\mathrm{n}=24$ ) hydrolyze approximately $0.9 \pm 0.3$ nmoles MeO-Suc-Ala-Ala-Pro-Val-pNA per 


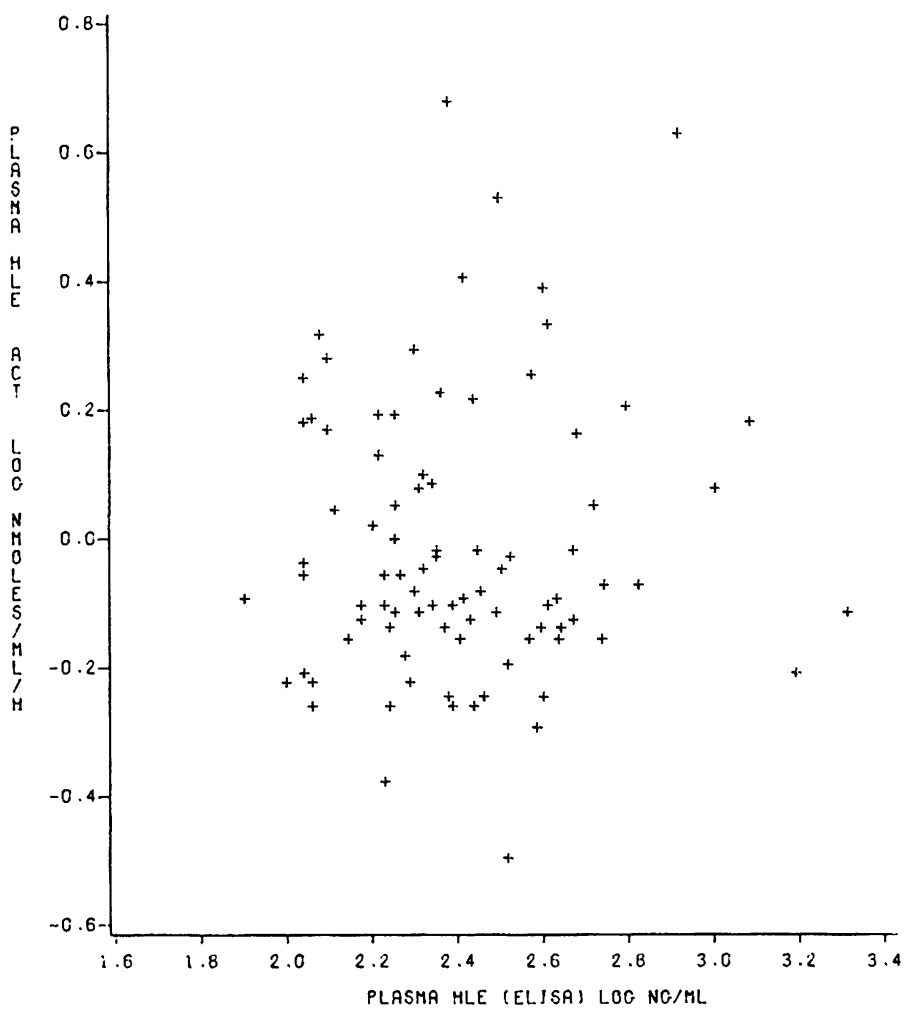

Fig. 3: HLE- $\alpha$ PI levels and HLE- $\alpha$ M activities in plasma of $87 \mathrm{RA}$ patients (note logarithmic transformation).

ml per hour. Although an extrapolation from this value to the amount of enzyme actually present as $\alpha$ M complex is not permissible, it can be estimated to be about 1-2 ng elastase/ml plasma. This is much less than the $84 \mathrm{ng}$ elastase/ml bound to $\alpha$ PI in normal plasma (see above). However, these values are quite compatible, when the known rates of complex formation and elimination are taken into account: the association rate constant of elastase $/ \alpha_{1}$ PI is 1.5 to 2 fold higher than that of elastase $/ \alpha_{2} M$ (27); together with the much higher plasma concentration of $\alpha_{1}^{2} \mathrm{PI}$ (approx. 10 times in molar terms) this accounts for a 15-20 fold higher rate of formation of the elastase/ $\alpha$ PI complex compared with the formation of the elastase $/ \alpha_{2} \mathrm{M}$ complex in plasma. Indeed, it was found that $90 \%$ of a small amount of radiolabelled elastase added to human serum was bound to $\alpha_{1} P I$ (28). The half-time of elimination of elastase $-\alpha{ }^{M}$ complexes $\frac{1}{1} \mathrm{n}$ man is approx. $12 \mathrm{~min}$, that of elastase $-\alpha_{1}$ PI is approx. $60 \mathrm{~min}$ (29). 
Using these numbers for a simple computer simulation experiment we calculated an influx of $47 \mathrm{ng} / \mathrm{ml} / \mathrm{h}$ of elastase into plasma (of healthy controls) creating steady state levels of elastase bound to $\alpha_{1}$ PI and to $\alpha_{2} \mathrm{M}$ of $90 \mathrm{ng} / \mathrm{ml}$ and $0.9 \mathrm{ng} / \mathrm{ml}$, respectively, - surprisingly close to our estimated values of 84 and 1 to $2 \mathrm{ng} / \mathrm{ml}$.

These calculations, although to be interpreted with caution, point to another important consideration. The flux of $47 \mathrm{ng}$ of elastase per ml plasma per hour would indicate a total turnover of HLE of 2 to $3 \mathrm{mg}$ per day, which is far below the estimated value of 300-400 mg elastase assumed to be released as a consequence of the normal life span of PMN leukocytes in healthy persons (28). It must be concluded, therefore, that only a small part of the elastase present in the neutrophil granules ever reaches the circulation. This might be one reason for the lack of correlation of plasma HLE levels and disease activity as observed here. Other reasons may be inflammation related alteration of the clearance rate (reticulo endothelial system) and altered rates of synthesis and consumption of proteinase inhibitors ( $\alpha_{1}$ PI is an acute phase reactant).

It is concluded that, although HLE is substantially elevated in the plasma of many RA patients, the plasma concentration of this enzyme by itself cannot serve as an indicator of disease activity. It is possible, however, that in longitudinal studies (within the same patients) changes in plasma HLE levels may be indicative of disease progression; indeed, changes in plasma levels of HLE have previously been shown to be indicative of disease progression in septicaenia(17).

\section{REFERENCES}

1. W. Mohr, and D. Wessinghage, The relationship between polymorphonuclear granulocytes and'cartilage destruction in rheumatoid arthritis, z. Rheumatol. 37:81 (1978).

2. S. Ruddy, Synovial fluid: Mirror of the inflammatory lesion in rheumatoid arthritis, in: "Rheumatoid arthritis," E. D. Harris, ed., Medcom Press, New York (1974).

3. L. J. Ignarro, Regulation of Iysosomal enzyme secretion: Role in inflammation, Agents and Actions 4:241 (1974).

4. P. M. Henson, Mechanisms of mediator release from inflammatory cells, in: "Mediators of Inflammation," G. Weissmann, ed., Plenum Press, New York (1974).

5. S. Honig, S. Hoffstein, and G. Weissmann, Leukocyte lysosomes and inflammation: The example of arthritis, Pathobiol. Annu. 8:315 (1978).

6. J. Saklatvala, A. J. Barrett, Identification of proteinases in rheumatoid synovium. Detection of leukocyte elastase, cathepsin $G$ and another serine proteinase, Biochim.Biophys. Acta 615:167 (1980). 
7. H. Menninger, R. Putzier, W. Mohr, D. Wessinghage, and K. Tillmann, Granulocyte elastase at the site of cartilage erosion by rheumatoid synovial tissue, $\underline{Z}$. Rheumatol. 39:145 (1980).

8. F. S. Steven, A. Torre-Blanco, and J. A. A. Hunter, A neutral protease in rheumatoid synovial fluid capable of attacking the telopeptide regions of polymeric collagen fibrils, Biochim. Biophys. Acta 405:188 (1975).

9. G. D. Virca, H. P. Schnebli, R. K. Mallya, and M. B. Pepys, Quantitation of leukocyte elastase, $\alpha_{1}$-proteinase inhibitor and $\alpha_{2}$-macroglobulin in synovial fluid, in preparation.

10. G. P. Kerby, and S. M. Taylor, Enzymatic activity in human synovial fluid from rheumatoid and non-rheumatoid patients, Proc. Soc. Exp. Biol. Med. 126:865 (1976).

11. N. M. Hadler, J. K. Spitznagel, and R. J. Quinet, Lysosomal enzymes in inflammatory effusions, J. Immunol. 123:572 (1979).

12. K. Kleesiek, S. Neumann, and H. Greiling, Determination of the elastase $\alpha_{1}$-proteinase inhibitor complex, elastase activity and proteinase inhibitors in the synovial fluid, Fresenius Z. Anal. Chem. 311:434 (1982).

13. J. D. Sandy, A. Sriratana, H. L. G. Brown, and D. A. Lowther, Evidence for polymorphonuclear-leucocyte-derived proteinases in arthritic cartilage, Biochem. J. 193:193 (1981).

14. M. Velvart, K. Fehr, A. Baici, G. Sommermeyer, M. Knöpfel, M. Cancer, P. Salgam, and A. Böni, Degradation in vivo of articular cartilage in rheumatoid arthritis by leucocyte elastase from polymorphonuclear leucocytes, Rheumatol. Int. 1:121 (1981).

15. A. J. Barrett, The possible role of neutrophil proteinases in damage to articular cartilage, Agents and Actions 8:11 (1978).

16. R. Egbring, W. Schmidt, G. Fuchs, and K. Havemann, Demonstration of granulocytic proteases in plasma of patients with acute leukemia and septicaemia with coagulation defects, Blood 49: 219 (1977).

17. M. Jochum, K. H. Duswald, E. Hiller and H. Fritz, Plasma levels of human granulocytic elastase- $\alpha_{1}$-proteinase inhibitor complex $\left(E-\alpha_{1} P I\right)$ in patients with septicemia and acute leukemia, in: "Progress in Clinical Enzymology II," D. M. Goldberg and M. Werner, eds., Masson Publ., N.Y., in press (1982).

18. L. P. Nelles, M. Jochum, K. H. Duswald and H. P. Schnebli, Increased levels of two distinct elastase like hydrolases in plasma during septicaemia, in: "Progress in Clinical Enzymology II," D. M. Goldberg an $\bar{d}$. Werner, eds., Masson Publ., N.Y., in press (1982).

19. R. K. Mallya, and B. E. W. Mace, The assessment of disease activity in rheumatoid arthritis using a multivariate analysis, Rheumatol. and Rehabil. 20:14 (1981).

20. S. Neumann, N. Hennrich, G. Gunzer, and H. Lang, Enzyme linked immuno-assay for human granulocyte elastase in complex with $\alpha_{1}$-proteinase inhibitor in plasma, J. Clin. Chem. Biochem. 19:232 (1981). 
21. H. P. Schnebli, Adjuvant-induced inflammatory disease in the rat: Plasma levels of peptide hydrolases and protease inhibitors reflect disease activity, Agents and Actions 9:497 (1979).

22. K. Nakajima, J. C. Powers, B. M. Ashe, and M. Zimmermann, Mapping the extended substrate binding site of cathepsin $G$ and human leucocyte elastase, J. Biol. Chem. 254:4027 (1978).

23. J. Saklatvala, Hydrolysis of the elastase substrate succinyltrialanine nitroanilide by a metal-dependent enzyme in rheumatoid synovial fluid, J. Clin. Invest. 19:794 (1977).

24. D. Neumeier, A. Fateh-Moghădam und G. Menzel, Humane Granulozyten-Elastase. I. Zur Methodik einer enzymimmunologischen Bestimmung des Elastase- $\alpha_{1}$-Proteinaseinhibitor-Komplexes, Fresenius Z. Anal. Chem. 311:389 (1982).

25. D. M. Ritchie, J.A. Boyle, J. M. McInnes, M. K. Jasani, T. G. Dalcos, P. Grieveson, and W. W. Buchanan, Clinical studies with an articular index for the assessment of joint tenderness in patients with rheumatoid arthritis, Q. J. Med. 147: 393 (1968).

26. R. K. Mallya, F. C. deBeer, H. Berry, E. D. B. Hamilton, B. E. Mace, and M. B. Pepys, Correlation of clinical parameters of disease activity in rheumatoid arthritis with serum concentration of C-reactive protein and exythrocyte sedimentation rate, J. Rheumatol., in press.

27. G. D. Virca, and J. Travis, Kinetics of association of human leukocyte elastase and cathepsin $G$ with human $\alpha_{2}$-macroglobulin, in preparation.

28. K. Ohlsson, and A. S. Olsson, Immunreactive granulocyte elastase in human serum, Z. Physiol. Chem. 359:1531 (1978).

29. K. Ohlsson, and C. $\bar{B}$. Laurell, The disappearance of enzyme-inhibitor complexes from circulation of man, Clin. Sci. Molec. Med. $51: 87$ (1976).

\section{ACKNOWLEDGEMENT}

We are grateful to Dr. S. Neumann and Dr. H. Lang (Merck, Darmstadt) for providing us with the materials for the ELISA assays. 